\title{
(")
}

ISSN 2238-4502

\section{CRÍTICA DE PROCESSO E ENSINO-APRENDIZAGEM DE LÍNGUA PORTUGUESA}

\author{
Eva Cristina Francisco \\ Instituto Federal São Paulo (IFSP- Avaré) \\ (evacristina@ifsp.edu.br)
}

\begin{abstract}
Resumo
A crítica genética tem ampliado seu campo de pesquisa no que diz respeito às novas reflexões sobre os processos de criação da obra de arte e faz jus a um novo conceito: a crítica de processo. No âmago destas reflexões deslumbram-se estratégias que podem trazer práticas inovadoras e exitosas para o ensinoaprendizagem da língua portuguesa, bem como das linguagens em geral. Nesse sentido, este artigo interpela reflexões sobre a crítica de processo no cinema, apresentando o papel da câmera como criadora da impressão da realidade e parte do processo criativo cinematográfico. A partir destas considerações, vislumbram-se possibilidades para a prática docente no ensino-aprendizagem do português brasileiro/linguagens. Para tanto, utilizamo-nos de referenciais teóricos sobre linguagem cinematográfica, pressupostos da crítica de processo, bem como da linguística aplicada
\end{abstract}

Palavras-chave: Crítica de processo. Cinema. Linguagem cinematográfica. Ensino-aprendizagem de Língua Portuguesa.

DOI: https://doi.org/10.32988/rep.v10n1.1560

Dossiê "Possibilidades de trabalho com a Língua Portuguesa" 


\section{Eva Cristina Francisco}

Graduada em Letras-Inglês (licenciatura) pela Universidade Estadual do Norte do Paraná (2004) e em Letras-Espanhol pelo Instituto Superior de Educação Plus (2014), Especializada em Metodologia de ensino de Língua Portuguesa e Estrangeira pelo Centro Universitário InternacionalUNINTER (2011), Mestra em Comunicação pela Universidade de Marília

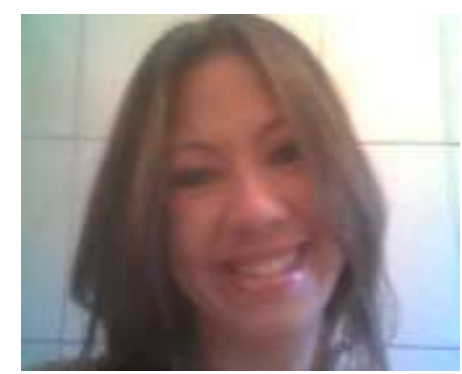
(2010), Doutora em Estudos da Linguagem pela Universidade Estadual de Londrina- UEL (2016) e Pósdoutora em Estudos da Linguagem, também pela UEL. Atualmente, constitui o corpo docente do Instituto Federal de São Paulo - IFSP (Campus Avaré), no qual é coordenadora do curso de Letras Português e Espanhol e coordenadora do PIBID- Língua Portuguesa. É docente permanente da pósgraduação stricto-sensu do IFSP (ProfEPT). É autora dos livros "Os signos educativos em felicidade por um fio: uma abordagem às relações étnico-raciais" e "Nos bastidores do cinema: a trajetória do papel às telas no filme Primo Basílio".

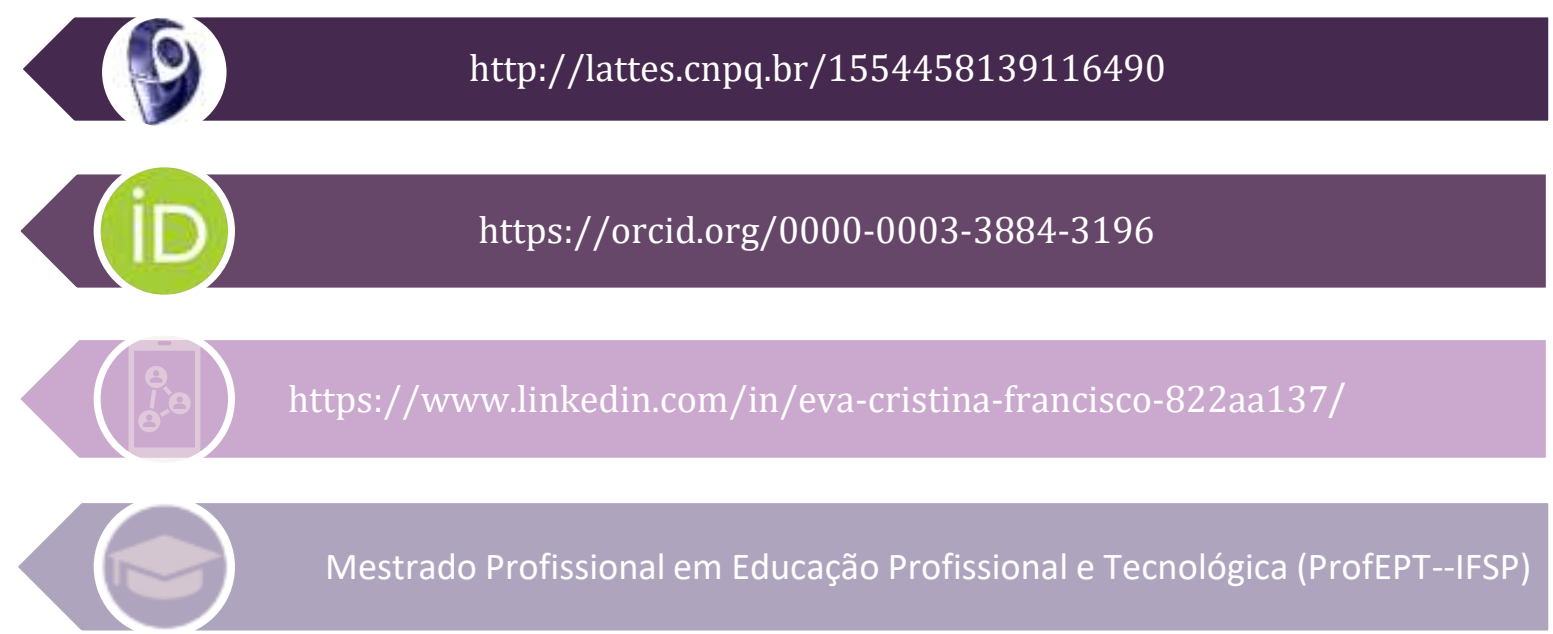

DOI: https://doi.org/10.32988/rep.v10n1.1560

Dossiê "Possibilidades de trabalho com a Língua Portuguesa"

v. 10

n.1

$1-16$

e021011

2021

Universidade Federal de Alfenas

Departamento de Letras - Instituto de Ciências Humanas e Letras

Rua Gabriel Monteiro da Silva, 700 - Alfenas/MG - CEP 317131-001 - Brasil

https://publicacoes.unifal-mg.edu.br/revistas/index.php/entreparenteses/about 


\title{
(")
}

ISSN 2238-4502

\section{CRÍTICA DE PROCESSO E ENSINO-APRENDIZAGEM DE LÍNGUA PORTUGUESA}

\author{
Eva Cristina Francisco ${ }^{1}$ \\ Instituto Federal São Paulo (IFSP- Avaré) \\ (evacristina@ifsp.edu.br)
}

Cinema e crítica genética: possibilidades para o ensino do PB $^{2}$

As pesquisas e curiosidades sobre o processo de criação vêm crescendo substancialmente em diversos âmbitos no que diz respeito à arte. Nesse sentido, a crítica genética e a crítica de processo têm contribuído em reflexões e descobertas que vão além dos manuscritos literários. ${ }^{3}$

Um exemplo disso é o cinema. Mas como pensar em crítica genética ao se deparar com imagens em movimento? Se a preocupação da crítica genética é o processo de evolução do texto, já podemos pensar em sua atuação no cinema ao observarmos os roteiros que são a gênese da criação cinematográfica. Embora este, muitas vezes, seja aberto a improvisos, com as contribuições dos atores e até mesmo possibilidades de que cenas e diálogos sejam escritos na hora da gravação, como assevera Ostrower:

Criar é, basicamente, formar. É poder dar uma forma a algo novo. Em qualquer que seja o campo de atividade, trata-se, nesse "novo", de novas coerências que se estabelecem para a mente humana, fenômenos relacionados de modo novo e compreendidos em termos novos. 0 ato criador abrange, portanto, a capacidade de compreender; e esta, por sua vez, a de relacionar, ordenar, configurar, significar. (OSTROWER, 1977. p. 2)

\footnotetext{
1 Graduada no curso de Licenciatura Letras-Inglês pela Universidade Estadual do Norte do Paraná (2004), Licenciatura em Letras-Espanhol pelo Instituto Superior de Educação Plus (2014), Especializada em Metodologia de ensino de Língua Portuguesa e Estrangeira pelo Centro Universitário Internacional- UNINTER (2011), Mestra em Comunicação pela Universidade de Marília (2010), Doutora em Estudos da Linguagem pela Universidade Estadual de Londrina- UEL (2016) e Pós-doutora em Estudos da Linguagem, também pela UEL.

2 Português Brasileiro

3 Este texto retoma reflexões feitas na tese de Doutorado em Estudos da Linguagem, ampliando o escopo da pesquisa para desdobramentos relacionados ao ensino-aprendizagem do Português Brasileiro.
}

DOI: https://doi.org/10.32988/rep.v10n1.1560

Dossiê "Possibilidades de trabalho com a Língua Portuguesa"

\begin{tabular}{|c|c|c|c|c|c|c|}
\hline Revista (Entre Parênteses) & Alfenas, MG & v. 10 & n.1 & $1-16$ & e021011 & 2021 \\
\hline
\end{tabular}




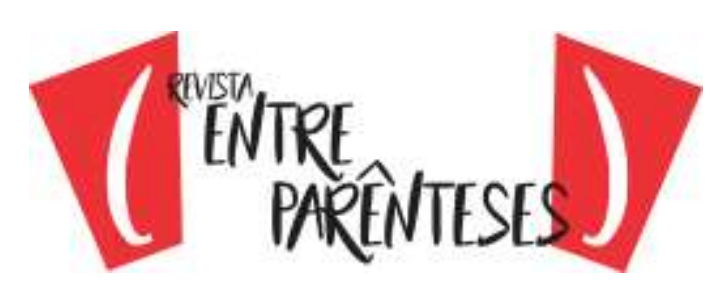

ISSN 2238-4502

Podemos atestar que o cinema é uma arte coletiva e depende de uma equipe bastante centrada em trabalhos individuais para que a arte seja efetivada. Divisões como direção, pré-produção, produção, fotografia, arte, som, montagem escolha da equipe e do elenco, análise técnica e cronograma são somente os elementos essenciais para que um filme aconteça.

Uma obra cinematográfica é capaz de nos fazer sorrir, chorar, emocionar, sofrer, torcer aguardando o desfecho de histórias cada vez mais criativas, inspiradoras, chocantes. A linguagem do cinema é a principal responsável por esses sentimentos causados ao espectador. Por meio dos personagens, do cenário, do conflito, da trilha sonora e muitos outros elementos, inserimo-nos na trama como se esta estivesse ocorrendo naquele momento e muitas vezes nos projetamos na narrativa, tal qual é a impressão de veracidade.

Dentre todos os elementos que compõem o processo de criação cinematográfica, interessa-nos, para aqui, a função da câmera, elemento substancial para a narrativa em imagens e grande responsável pela criação da impressão de realidade. É imperativo levar em conta, no caso de uma análise da imagem, que "a função comunicativa de uma mensagem visual, explícita ou implícita, determina com força sua significação" (JOLY, 2010, p. 59).

Com as tomadas de decisão orientadas pelo diretor do filme, o cameraman executa seu trabalho proporcionando o efeito da profundidade de campo, isto é, a recriação da história por meio das imagens ali projetadas.

A criação, a recriação ou a tradução, nesse caso, intersemiótica, muito devem aos efeitos que a câmera engendra. Desse modo, perceberemos aqui que a crítica genética vai além dos documentos de processo manuscritos e ressurge dentro da linguagem cinematográfica. Para corroborar a ideia exposta, faremos a análise de alguns recursos que a câmera oferece para o processo de criação por meio das imagens em movimento. Para tanto, nos utilizaremos de uma análise da linguagem cinematográfica do filme Primo Basílio, uma transcodificação do romance de Eça de Queirós (1848) para o longa de Daniel Filho (2007):

A crítica genética assume, desse modo, aquilo que Daniel Ferrer (2000) chamou de 'vocação artística'. Ele afirma que o desenvolvimento dos estudos genéticos sustenta-se nos esforços de alguns pesquisadores de 'promover uma reflexão da crítica genética que atravesse as fronteiras dos gêneros e das artes' e vê que esse é o caminho para os estudos genéticos sobreviverem no século XXI. (SALLES, 2008, p. 16)

Além da referida sobrevivência dos estudos da gênese da criação que a autora vislumbra, podemos evidenciara cada subitem deste trabalho, como esses estudos lançam luz sobre a abordagem a estudos da língua portuguesa em diversos âmbitos de investigação, tais

DOI: https://doi.org/10.32988/rep.v10n1.1560

Dossiê "Possibilidades de trabalho com a Língua Portuguesa"

\begin{tabular}{|l|c|c|c|c|c|c|} 
Revista (Entre Parênteses) & Alfenas, MG & v. 10 & n.1 & $1-16$ & e021011 & 2021 \\
\hline
\end{tabular}




\section{(")}

ISSN 2238-4502

como: análise do discurso, semântica, semiótica, morfologia, leitura e produção do texto, para citar alguns.

A Câmera e seu papel criador: subsídios para a leitura e produção textuais

Após breves considerações sobre o cinema e a crítica genética, bem como possibilidades de ampliação dos estudos para a prática docente, examinemos uma das modalidades da criação da imagem, nesse caso, o papel da câmera enquanto agente ativo de registro da realidade da matéria e de criação da realidade fílmica. Segundo Martin (2003), a emancipação da câmera teve grande importância na história do cinema. 0 nascimento da filmadora enquanto arte se deu quando os diretores inovaram, deslocando a câmera ao longo de uma mesma cena.

Por muito tempo a câmera permaneceu fixa como se o espectador estivesse assistindo a uma peça teatral. Todavia, a partir de 1900, o Inglês G. A. Smith "libertou" a câmera de sua posição estática, o que fazia possível modificar o plano de vista do quadro fílmico. "A câmera torna-se móvel como olho humano como olho do espectador ou do herói do filme. 0 diretor impõe seus diversos pontos de vista ao espectador". (MARTIN, 2003, p. 31).

Do trabalho com a câmera, podemos lançar desdobramentos para o ensinoaprendizagem de Leitura e Produção de textos, por exemplo. Nesse bojo, vale problematizar junto aos alunos sobre em que perspectiva eles identificam a mensagem principal de um texto, assim como a perspectiva que a câmera nos traz na exibição de um filme. Ademais, ao produzir um texto, dentro dos mais variados gêneros, qual o posicionamento que o aluno poderá tomar, com base nos artifícios gerados pelo trabalho da câmera. Mesmo porque, de acordo com (FIORIN; PLATÃO, 1996, p. 14), o texto "não é um amontoado de frases, ou seja, nele as frases não estão pura e simplesmente dispostas umas após as outras, mas estão relacionadas entre si". Naturalmente, antes deste tipo de atividade, cabe ao docente elucidar alguns conceitos sobre a linguagem cinematográfica e exibir algum vídeo, mesmo que de curta duração para ilustrar. Esta atividade pode ser adaptada a todos os níveis de ensino.

A câmera deixa a passividade para se tornar ativa, atriz, narradora, criadora e é assim que podemos instigar a prática de leitura e produção textual aos discentes. Analisemos, a seguir, duas contribuições da câmera para com o processo de criação: os ângulos de filmagem e os movimentos de câmera.

Ângulos de filmagem: Semiótica e Discurso

Somado a todos os elementos que compõem a linguagem cinematográfica, a angulação das filmagens, ou seja, o ângulo usado no enquadramento é um grande aliado na

DOI: https://doi.org/10.32988/rep.v10n1.1560

Dossiê "Possibilidades de trabalho com a Língua Portuguesa"

\begin{tabular}{|l|l|l|l|l|l|l|} 
Revista (Entre Parênteses) & Alfenas, MG & v. 10 & n.1 & $1-16$ & e021011 & 2021 \\
\hline
\end{tabular}


gênese da criação cinematográfica. A angulação é a perspectiva tomada pela percepção visual do receptor ao apreender as figuras apresentadas no quadro fílmico. Quando não são diretamente justificados por uma situação ligada à ação, ângulos de filmagem excepcionais podem adquirir uma significação psicológica precisa. Vejamos, no quadro abaixo, elaborado com base nas definições do autor Marcel Martin (2003):

Quadro no 1 - Quadro demonstrativo da posição da câmera

\begin{tabular}{|c|c|}
\hline Câmera Normal & $\begin{array}{c}\text { É posicionada na altura dos olhos do } \\
\text { espectador. }\end{array}$ \\
\hline Câmera Alta ou "Plongeé” & A ação é filmada de cima para baixo. \\
\hline Câmera Baixa ou Contra-"Plongeé" & A filmagem é realizada de baixo para cima. \\
\hline Câmera Subjetiva & $\begin{array}{c}\text { A câmera se posiciona no ponto de vista de } \\
\text { um dos personagens. }\end{array}$ \\
\hline Câmera objetiva & $\begin{array}{c}\text { A câmera assume o papel de narradora da } \\
\text { história. }\end{array}$ \\
\hline
\end{tabular}

Este recurso não é somente usado para dar variedade ao aspecto das imagens ou mostrar melhor suas dimensões básicas. Ele também pode causar certos efeitos aptos à expressão de sentimentos, emoções e ideias. Quando os ângulos não se justificam diretamente devido à ação, podem trazer precisas significações psicológicas, como atesta Salles:

De modo análogo, ao acompanhar diferentes processos, observamos na intimidade da criação um contínuo movimento de tradução intersemiótica, aqui vista como transcodificação de diferentes linguagens (...) todo processo de criação é um percurso tradutório que nos oferece um instrumento fértil, para discutirmos a poética contemporânea. (SALLES, 2006, p. 157)

As ilustrações a seguir, que representam a transmutação de formas da linguagem literária para a fílmica, podem corroborar que relações de superioridade e inferioridade, poder e submissão, humilhação e glória, solidão e mesquinhez podem ganhar relevo com o uso dos ângulos.

DOI: https://doi.org/10.32988/rep.v10n1.1560

Dossiê "Possibilidades de trabalho com a Língua Portuguesa"

\begin{tabular}{|l|l|l|l|l|l|l|}
\hline Revista (Entre Parênteses) & Alfenas, MG & v. 10 & n.1 & $1-16$ & e021011 & 2021 \\
\hline
\end{tabular}




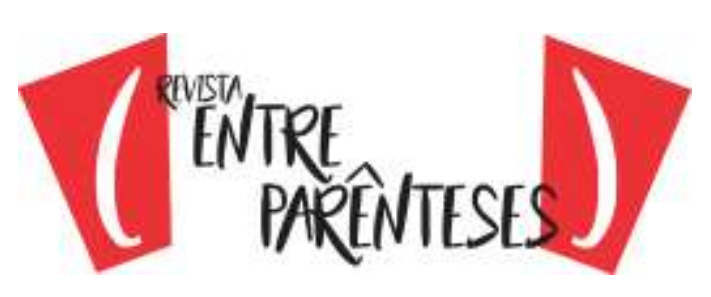

ISSN 2238-4502

Imagem 1: Juliana filmada em "contra-plongée"

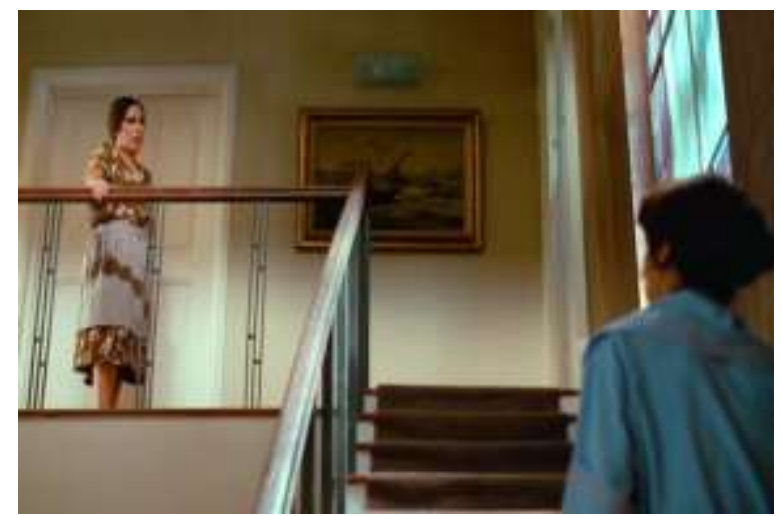

Na cena que a figura 1 ilustra, Juliana maltratava Luísa porque havia sido ofendida por Jorge devido à roupa mal passada. Para que fosse ilustrado o grau de superioridade de Juliana em relação à patroa, devido ao segredo que conhece, é usada a angulação vertical, também denominada contra-plongée. Percebe-se que a câmera objetiva está abaixo do nível usual do olhar espectador. 0 efeito de significação é a superioridade de Juliana, a exaltação, o triunfo de estar ocupando a posição de patroa ao confrontar Luísa. Detecta-se a distância entre a empregada e a patroa. A vítima da chantagem, de costas, se encontra bem abaixo, mostrando dificuldade, no decorrer da sequência, em alcançar o nível em que Juliana se encontra.

Imagem 2: Luisa filmada em ângulo "plongée"

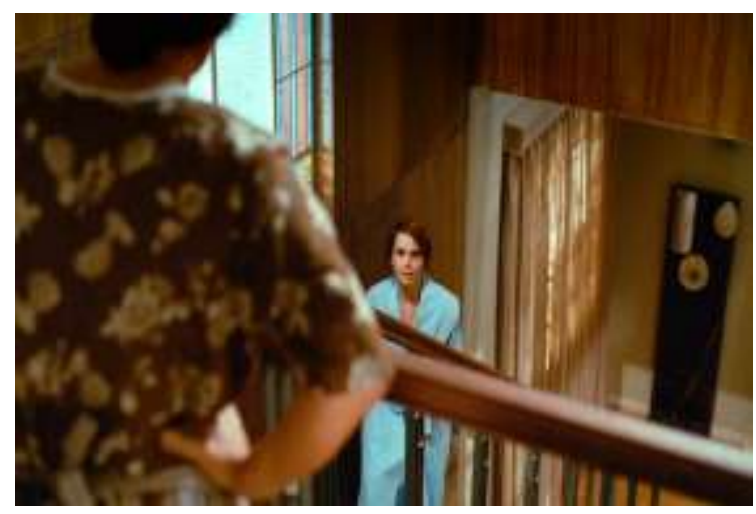

Na sequência seguinte, ocorre o oposto. A câmera focaliza Luísa de frente com a angulação oblíqua, também classificada como plongée. Na fotografia desta cena, o efeito causado é a diminuição da personagem Luísa criando a impressão de que a vítima da chantagem é esmagada moralmente, rebaixada, ameaçada. A figura é literalmente diminuída, comparandose a dimensão das costas de Juliana com a imagem inteira de Luísa. Caracteriza-se, nessas duas

DOI: https://doi.org/10.32988/rep.v10n1.1560

Dossiê "Possibilidades de trabalho com a Língua Portuguesa" 


\section{(")}

ISSN 2238-4502

últimas figuras, o chamado jogo de cenas, que é a combinação dos ângulos "plongée" e "contraplongée."

Ao assistir ao filme, nota-se que, conforme a empregada eleva seu tom de voz, sua imagem é amplificada; por outro lado, a aproximação da câmera em Luísa, ainda no mesmo ângulo, demonstra seu medo e submissão a Juliana. Podemos ver, nas duas últimas ilustrações, a subjetividade da câmera agregando sugestões no ponto de vista do espectador. Ela pôde modificar nosso ponto de vista de um plano a outro, colocando a submissão de Luísa versus o domínio de Juliana.

Aqui podemos evidenciar dois campos de estudos da linguagem: análise do discurso, tanto na perspectiva de Pecheux quanto na visão de Charaudeau. Também podemos promover estudos da semiótica norte-americana, mais especificamente a teoria dos signos interpelada por Peirce.

Para os estudos do discurso, considerando a teoria pecheutiana, podemos trabalhar os discursos inferidos pelos ângulos de filmagem, bem como as ideologias ali apresentadas (na cena ilustrada: empregada versus patroa; traição da esposa; chantagem da empregada). 0 que projeta um emaranhado de "atitudes e de representações que não são nem "individuais" nem "universais" mas se relacionam mais ou menos diretamente a posições de classe ${ }^{4}$ em conflito umas com as outras. (PÊCHEUX; FUCHS, [1975] 1997, p. 166).

Já para a teoria charaudiana, é possível analisar em uma perspectiva semiolinguística, isto é, trazer os signos apresentados nas cenas em confluência aos elementos linguísticos provenientes do discurso ali apresentado. Nessa perspectiva podemos salientar para os estudantes que o ato de linguagem não pode ser considerado como um processo comunicativo direto e transparente entre destinatário e emissor. Contrariamente a isto, podemos identificar o referido ato como sendo um processo de encenação através do qual os seres sociais se entregam em "uma expedição e uma aventura" (CHARAUDEAU, 2008, p. 56)

No caso do trabalho com a semiótica, identificamos a possibilidade de abordar pelo menos uma das tricotomias de Peirce (2005) ou até mesmo a fenomenologia (primeiridade, secundidade e terceiridade) conforme os ângulos de filmagem são estabelecidos. Tais atividades têm um foco mais no ensino superior, mas nada impede de ser adaptada com uma linguagem mais acessível e sem excesso de teoria para outros níveis de ensino.

Movimentos de câmera: possibilidades com Semântica e Morfologia

Os movimentos de câmera também são considerados contribuintes na gênese da criação cinematográfica. Assim como os enquadramentos, planos e angulações, os movimentos

${ }^{4}$ Grifo nosso

DOI: https://doi.org/10.32988/rep.v10n1.1560

Dossiê "Possibilidades de trabalho com a Língua Portuguesa"

\begin{tabular}{|l|c|c|c|c|c|c|} 
Revista (Entre Parênteses) & Alfenas, MG & v. 10 & n.1 & $1-16$ & e021011 & 2021 \\
\hline
\end{tabular}




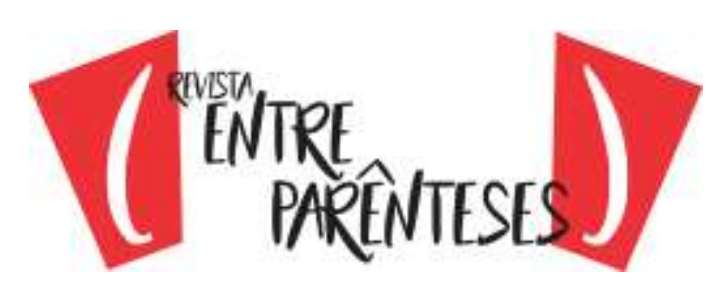

ISSN 2238-4502

Os dois movimentos de câmera mais utilizados em um filme são denominados "panorâmica" e "traveling". O primeiro é o movimento realizado pela câmera em torno de seu próprio eixo sobre um suporte fixo e pode ser distinguido em três tipos: "panorâmica vertical", "panorâmica horizontal" e "panorâmica oblíqua," conforme já distinguidos no quadro 3.

As panorâmicas podem se subdividir quanto às funções em três espécies: a descritiva, a expressiva e a dramática. Quanto à primeira espécie, podemos descrever a sequência que dá início à trama, quando a câmera filma, lentamente, o Teatro Municipal de São Paulo.

Esse movimento foi realizado já no início do filme para descrever o espaço onde começaria a trama, localizando o espectador na história. Ao assistirmos ao filme, podemos ver, de início, o topo do Teatro. Em seguida, a continuação dessa filmagem mostra o nome do estabelecimento e, por fim, o local é filmado como um todo. É possível observar nessa sequência a panorâmica descritiva vertical para baixo, que tem como finalidade explorar o espaço e é utilizado também, em geral, na introdução ou conclusão de um filme.

Já a panorâmica expressiva está destinada a sugerir uma impressão ou uma ideia e, muitas vezes, pode ter muita importância ao atribuir ou sugerir sentidos a uma determinada sequência. Nas cenas que mostram o recomeço do romance entre os primos, nas quais Luísa deixa de resistir às investidas do amante e se entrega a Basílio, identificamos uma panorâmica expressiva vertical para baixo. É tarde da noite. Luísa é avisada de que Basílio a espera. Desce as escadas em direção à sala e um movimento de câmera panorâmica vertical para baixo a acompanha até que chegue à sala. À medida que desce os degraus, a escuridão vai encobrindo sua imagem. Nesse movimento está inferida a ideia de que, a partir daquele momento, a vida de Luísa caminha para o abismo e para as trevas. Será a primeira vez que trairá o marido. A descida conecta-se a significados muito marcados na imagética ocidental, remetendo à ideia da descida aos infernos, pois, no imaginário ocidental, o inferno fica abaixo do solo, em contraposição ao céu, localizado nas alturas. A sequência marca o momento da trama em que Luísa inicia a queda moral. Outro contraste, ou contraposição, é a do claro/escuro que se alia ao sentido anterior; o inferno é tradicionalmente ligado às trevas e o céu à luz.

E por fim, contemos com um exemplo de função dramática. As panorâmicas, nessa função, exercem papel direto na narrativa fílmica. Além disso, podem estabelecer relações espaciais entre os elementos do quadro fílmico, o que causa a impressão de conflito. Pela panorâmica dramática vertical para cima, utilizada na sequência descrita, anuncia-se o conflito da história:

Luísa sai ao encontro de Basílio e acaba encontrando Sebastião no caminho. Assustada, depois de certa insistência do amigo do casal, ela resolve aceitar o convite para almoçar com ele. Ao chegar ao local do encontro com o amante, percebe que este acabara de sair, pois vê o cigarro ainda quase aceso no cinzeiro. Furiosa, volta para casa e vai sala adentro gritando, nervosa. A câmera segue Luísa, em plano americano, subindo as escadas furiosamente em direção ao quarto onde encontra Juliana que, àquela hora, ainda começa a arrumação do quarto, o que a deixa muito irritada. A partir dessa discussão, começam as chantagens e

DOI: https://doi.org/10.32988/rep.v10n1.1560

Dossiê "Possibilidades de trabalho com a Língua Portuguesa"

\begin{tabular}{|l|l|l|l|l|l|l} 
Revista (Entre Parênteses) & Alfenas, MG & v. 10 & n.1 & $1-16$ & e021011 & 2021 \\
\hline
\end{tabular}




\section{(")}

ISSN 2238-4502

ameaças. Luísa ofende a empregada e a manda embora. Juliana acaba revelando que possui as cartas trocadas entre a patroa e o amante e pode entregá-las a Jorge a qualquer momento. Cena esta que dá início a todo o sofrimento pelo qual Luísa passará no restante da narrativa.

Quanto ao "traveling", trata-se do deslocamento da câmera (do olhar): durante este movimento o ângulo entre o eixo da objetiva e a trajetória do deslocamento permanece constante. Em outras palavras, é a câmera fixa no carro que se move. Conforme a realização do deslocamento, pode-se identificar tipos de "traveling", conforme já exposto no quadro de número 2, sob a perspectiva de Martin (2003).

Para exemplificar a utilização de um "traveling" para frente, referimo-nos à sequência que mostra Jorge saindo para o trabalho e deixando a esposa a fechar o portão. Juliana já estava chantageando a patroa e esta sofria intensamente quando ficava a sós com a empregada. Observando a cena, percebe-se que o "traveling" para frente enfatiza a tristeza de Luísa ao ficar em casa com Juliana, quando o marido se ausenta. À medida que ela fecha o portão, a câmera se aproxima até que a personagem apareça em primeiro plano expressando tristeza nos olhos. A filmagem sugere que a partir do momento em que o portão se fecha, a personagem estará enjaulada e pressionada pela chantagem de Juliana. Na realidade, esse momento é pura linguagem fílmica, a imagem diz tudo, não há necessidade de palavras, ela recria e dá vida à história.

Tomemos, agora, uma das sequências do final da trama, na qual Basílio conversa com o amigo sobre a morte de Luísa, enquanto sobe as escadas do mesmo teatro em que se deu o início da narrativa fílmica. Nesta cena é realizado um "traveling" para trás. A câmera afasta-se à medida que Basílio e seu amigo se aproximam do quadro fílmico. No diálogo, Basílio age com total indiferença ao falar sobre o fato ocorrido com a própria prima:

\footnotetext{
-"Sinceramente, eu sempre achei essa sua relação com a prima meio "recordar é viver". Que "cá" entre nós, ela não era lá aquelas coisas, confessa...

- É... uma esposinha, mas tinha potencial. Ah! Isso tinha... Tadinha... morreu. Ah! Mas antes ela do que eu..."

(Diálogo retirado do capítulo 23 do filme Primo Basílio)
}

Ao terminar de subir as escadas, Basílio dirige-se aos assentos do teatro e, lá, já tenta investir em outra conquista como se a cada degrau, ou a cada passo, uma nova aventura se aproximasse. 0 recuo da câmera pode simbolizar um sentimento de repúdio à atitude cínica e impiedosa de Basílio. Recurso semelhante é utilizado em O Crime do Padre Amaro, quando, ao final, a câmera realiza um "traveling" para trás retirando-se da igreja e distanciando-se do padre que oficia a cerimônia fúnebre.

Unindo o diálogo à descrição da cena com a utilização do referido movimento de câmera, vemos a possibilidade de estudos semânticos, ou seja, as investigações sobre o

DOI: https://doi.org/10.32988/rep.v10n1.1560

Dossiê "Possibilidades de trabalho com a Língua Portuguesa"

\begin{tabular}{|l|c|c|c|c|c|c|} 
Revista (Entre Parênteses) & Alfenas, MG & v. 10 & n.1 & $1-16$ & e021011 & 2021 \\
\hline
\end{tabular}




\title{
(")
}

ISSN 2238-4502

significado (CANÇADO, 2008). Ao observar cada palavra do diálogo apresentado em consonância com a linguagem do cinema, inferimos os mais diversos significados e podemos chegar ao mais profundo nível de interpretação das mensagens que o diretor do filme tenta nos transmitir, por meio das semânticas lexical, formal e argumentativa. Além desses exemplos, ainda há o "traveling" lateral e o vertical. Não é válido para este trabalho discorrer longamente sobre estes, mesmo porque o primeiro apresenta a função mais frequente de narração e descrição sendo muito comum e raramente expressivo e o segundo é usado raras vezes.

Pudemos perceber diante das análises expostas que o cinema está cada vez mais próximo de ser explorado no que diz respeito à pesquisa da gênese da criação e desdobrar estes conhecimentos em prol de práticas inovadoras e exitosas em sala de aula pode promover melhorias no ensino aprendizagem de língua portuguesa/linguagens. Como exemplos da crítica de processo, consoante Salles (2006, p. 161) têm-se os "making of's" que, "quando são realmente documentários de processo de criação (e não peças de divulgação de filmes), também fazem dos processos documentados obras".

Os recursos cinematográficos, mais especificamente, o papel da câmera na criação fílmica mostra a tradução de códigos recriando e/ou transcriando a narrativa. 0 filme intensifica a história por narrá-la através de imagens em movimento. Ao determinar uma tomada de decisão, um ângulo, um enquadramento ou um movimento de câmera, o diretor realiza esse processo de criação levando o espectador a viver a história em tempo real, independente do tempo, do espaço e da ação. Outrossim, nota-se que o poder de criação da câmera, no filme analisado, teve considerável participação no processo de transcodificação da linguagem narrativa literária para o código audiovisual. E a crítica de processo pode explorar ainda mais recursos do cinema para ampliar os estudos da gênese da criação, já que vivemos em um mundo extremamente visual, pois, conforme Ostrower:

\begin{abstract}
“(...) a nossa capacidade de comunicar conteúdos expressivos não se restringe às palavras; nem são elas o único modo de comunicação simbólica. Existem, na faixa de mediação significativa entre nosso mundo interno e o externo, outras linguagens além das verbais. Diríamos que, ao simbolizarem, as palavras caracterizam uma via conceitual. Essencialmente porém, no cerne da criação está a nossa capacidade de nos comunicarmos por meio de ordenações, isto é, através de FORMAS. (OSTROWER, 1977, p. 9)."
\end{abstract}

Diante do exposto, finalizamos estas reflexões agregando ainda os estudos morfológicos da Língua Portuguesa aos estudos genéticos do cinema. Mesmo no ensino superior, a própria definição ${ }^{5}$ de um dos elementos da formação da estrutura do Português Brasileiro (CÂMARA JR., 1975) causa inquietação aos discentes. A fim de uma forma de deixar a terminologia mais leve e instigar os estudos morfológicos, entrevemos a possibilidade de se

${ }^{5}$ No que diz respeito à morfologia.

DOI: https://doi.org/10.32988/rep.v10n1.1560

Dossiê "Possibilidades de trabalho com a Língua Portuguesa"

\begin{tabular}{|l|l|l|l|l|l|l} 
Revista (Entre Parênteses) & Alfenas, MG & v. 10 & n.1 & $1-16$ & e021011 & 2021 \\
\hline
\end{tabular}




\section{Referências}

CÂMARA JR., Joaquim Mattoso. História e Estrutura da Língua Portuguesa. Rio de Janeiro: Padrão, 1985.

CANÇADO, Márcia. Manual de semântica: noções básicas e exercícios. 2. ed. revisada. Belo Horizonte: Editora UFMG, 2008.

CHARAUDEAU, Patrick. Linguagem e discurso: modos de organização. Trad. Angela M. S. Correa \& Ida Lúcia Machado. São Paulo: Contexto, 2008.

CHESHIRE, David. Manual de Cinematografía. H-Blume Ediciones, Madrid, 1979.

FIORIN, J. L.; SAVIOLI, F. P. Lições de texto. Leitura e redação. São Paulo: Ática,1996.

FRANCISCO, Eva Cristina. Nos bastidores do Cinema: a trajetória do papel às telas no filme Primo Basílio. 1. ed. Londrina: EDUEL, 2021.

JOLY, Martine. Introdução à análise da imagem.14 ed. Campinas: Papirus, 2010. MARTIN, Marcel. A Linguagem cinematográfica. São Paulo: Brasiliense, 2003.

OSTROWER, Fayga. Criatividade e Processo de Criação. Rio de Janeiro: Vozes, 1977.

PÊCHEUX, M.; FUCHS, C. A propósito da Análise Automática do Discurso: atualização e perspectivas. Tradução de Péricles Cunha. In: GADET, F.; HAK, T. (Org.). Por uma análise automática do discurso: uma introdução à obra de Michel Pêcheux. 3. ed. Campinas: Unicamp, 1997 [1975].

PEIRCE, Charles Sanders. Semiótica. São Paulo: Perspectiva, 2005

SALLES, Cecília de Almeida. Redes da Criação: construção da obra de arte. São Paulo: Edit. Horizonte, 2006.

DOI: https://doi.org/10.32988/rep.v10n1.1560

Dossiê "Possibilidades de trabalho com a Língua Portuguesa"

\begin{tabular}{|l|l|l|l} 
Revista (Entre Parênteses) & Alfenas, MG & v. 10 & n 1 \\
\hline
\end{tabular}




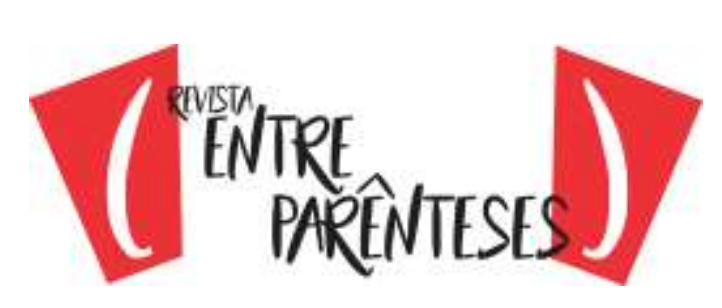

ISSN 2238-4502

\title{
REVIEW OF PORTUGUESE LANGUAGE PROCESS AND TEACHING-LEARNING
}

\author{
Eva Cristina Francisco \\ Instituto Federal São Paulo (IFSP- Avaré) \\ (evacristina@ifsp.edu.br)
}

\begin{abstract}
Genetic criticism has broadened its field of research with regard to new reflections on the creation processes of the work of art and does justice to a new concept: process criticism. At the heart of these reflections are strategies that can bring innovative and successful practices to the teaching and learning of the Portuguese language, as well as languages in general. In this sense, this article challenges reflections on the process criticism in cinema, presenting the role of the camera as the creator of the impression of reality and part of the creative cinematographic process. From these considerations, possibilities for teaching practice in the teaching-learning of Brazilian Portuguese / languagesare glimpsed. For that, we use theoretical references on cinematographic language, assumptions of process criticism, as well as applied linguistics.
\end{abstract}

Keywords: Process criticism. Movie theater. Cinematic language. Portuguese language teaching and learning.

DOI: https://doi.org/10.32988/rep.v10n1.1560

Dossiê "Possibilidades de trabalho com a Língua Portuguesa"

\begin{tabular}{|l|l|l|r|} 
Revista (Entre Parênteses) & Alfenas, MG & v. 10 & n. 1 \\
\hline
\end{tabular}

Universidade Federal de Alfenas

Departamento de Letras - Instituto de Ciências Humanas e Letras

Rua Gabriel Monteiro da Silva, 700 - Alfenas/MG - CEP 317131-001 - Brasil

https://publicacoes.unifal-mg.edu.br/revistas/index.php/entreparenteses/about 


\title{
(")
}

ISSN 2238-4502

\section{ENCUESTA SOBRE ESCRITURA Y HABITOS DE ESCRITURA ENTRE ESTUDIANTES DE INGENIERÍA}

\author{
Eva Cristina Francisco \\ Instituto Federal São Paulo (IFSP- Avaré) \\ (evacristina@ifsp.edu.br)
}

\begin{abstract}
Resumen
La crítica genética ha ampliado su campo de investigaciónen torno a nuevas reflexiones sobre losprocesos de creación de la obra de arte y está a la altura de unnuevo concepto: la crítica de procesos. Enel centro de estas reflexiones se encuentranlasestrategias que pueden aportar prácticasinnovadoras y exitosas a laenseñanza y elaprendizaje de lalengua portuguesa, así como de laslenguasen general. En este sentido, este artículo desafía reflexiones sobre elproceso crítico enel cine, presentando el papel de lacámara como creadora de laimpresión de realidad y parte delprocesocreativo cinematográfico. A partir de estas consideraciones, se vislumbranposibilidades para lapráctica docente enlaenseñanzaaprendizajedel português brasileño / lenguaje. Para ello, utilizamos referencias teóricas sobre lenguaje cinematográfico, supuestos de crítica de procesos, así como lingüística aplicada.
\end{abstract}

Palabras clave: Crítica de processos. Cine. Lenguaje cinematográfico. Enseñanza y aprendizaje de lalengua portuguesa

DOI: https://doi.org/10.32988/rep.v10n1.1560

Dossiê "Possibilidades de trabalho com a Língua Portuguesa" 